\title{
Collaborating on Multi-party Information Systems Development Projects: A Collective Reflection-in-Action View
}

\author{
by \\ Natalia Levina \\ New York University \\ Stern School of Business \\ Information Systems Group/ IOMS \\ 44 West Fourth St, Suite 8-78 (KMC) \\ New York, NY 10012 \\ Office Phone: 212-998-0850 \\ Fax: $\quad$ 212-995-4228 \\ Email: nlevina@stern.nyu.edu
}

This manuscript is conditionally accepted at Information Systems Research journal.

Please do not quote without author's permission.

This paper is based on the PhD Dissertation that was a finalist in the ICIS Dissertation Competition 2002 and in the Academy of Management Technology and Innovation Management (TIM) Division Dissertation Competition in 2002. 


\title{
Collaborating on Multi-party Information Systems Development Projects: A Collective Reflection-in-Action View
}

\begin{abstract}
Growth of business-to-consumer (B2C) applications such as electronic storefronts, catalogues, and customer support websites has drawn a great number of diverse stakeholders into the IS Development (ISD) practice. Marketing, strategy, and graphic design specialists have joined a variety of technical professionals and business stakeholders in developing B2C applications. Oftentimes, these professionals work for different organizations with different histories, cultures, and reward structures. A longitudinal qualitative field study of a B2C application development project was undertaken in order to build an indepth understanding of the collaborative practices of diverse professionals in ISD projects. The paper proposes that the multi-party collaborative practice can be understood as a "collective reflection-in-action" cycle through which an IS design emerges as a result of agents producing, sharing, and reflecting upon material objects. Agents from diverse backgrounds exert different influences over emergent designs depending on their organization, profession, and project involvement-based power relations. These power relations shape whether collaborators "add to" "ignore," or "challenge" the work produced by others. In turn, agents' actions either reinforce or transform existing power relations depending on who gets to claim credit for and ownership of the emergent design. Implications for the study of boundary objects, team diversity, organizational learning, and contemporary ISD are drawn.
\end{abstract}




\section{Introduction}

The emergence of the World Wide Web technologies has added several new facets to the ISD process. The spread of the new platform brought with it the rapid growth of B2C applications. Such systems have been associated with increasing involvement of marketing and advertising groups, which provide expertise on how to entice consumers to adopt new applications, into ISD projects. At the same time, technical professionals have become increasingly diverse in their skills as they specialize in handling rapidly evolving technical platforms. In addition, B2C applications are often seen as strategic by organizations, which not only invest a significant amount of resources in them, but also often rely on them as a primary means of interacting with customers. Many of these systems are developed under extreme time pressure as companies try to gain competitive benefits from being the first movers in the market.

Nowadays an ISD project involves people from different walks of life-strategists, network specialists, code developers, functional analysts, creative professionals, brand specialists, and various business unit managers (business stakeholders)-working together to design and implement new B2C offerings. Some of them, like strategy consultants, have not typically participated in IS development before. Others, like artists, are often not used to working in traditional corporations. With the growth of outsourcing, many web-based applications involve sourcing all or part of the development with a specialized firm. Contemporary ISD settings combine competencies of these diverse actors on integrated ISD project teams with the hope of igniting creative sparks (Leonard and Swap 1999). However, the results produced by professionally and organizationally diverse teams differ drastically in quality and kind (Carlile 2002, Dougherty 1992). While the potential for producing useful outcomes is high, the potential for conflict and stagnation is even higher (Guinan, et al. 1998, Polzer, et al. 2002, Reagans and Zuckerman 2001). The

purpose of this paper is to address two questions: 1) how people from diverse walks of life and 
organizational settings collaborate-work together ${ }^{1}$-on ISD projects, and 2) how their diverse backgrounds influence systems that they design.

Insights on these questions are drawn from a qualitative longitudinal field study of a B2C webdevelopment project. I have adopted a practice-theoretical stance (Bourdieu 1977, Giddens 1984) and focused on what people do and how their actions shape and are shaped by organizational, professional, and project involvement-based power relations. Using Schön's (1983) reflection-in-action notion, I propose that collaboration on multi-party ISD can be understood as a collective reflection-in-action cycle which shapes and is shaped by situated power relations among project participants. By exploring collaborative practices of different kinds of developers and business stakeholders on a B2C application development project, this paper makes a contribution to the ISD literature, which has been primarily focused on understanding collaboration between developers and users or among technical developers.

\section{Perspectives on Collaboration in ISD}

\section{User-Developer Collaboration in ISD}

One kind of multi-party collaboration that has been extensively explored in ISD literature is the collaboration between professional developers and users. These studies have used multiple perspectives and methods and may offer insights into the investigation of collaborative practices among developers. The rich literature on the subject can be divided into two perspectives: rational and political (Robey and Markus 1984). Rational perspective views ISD as a process with an identifiable, agreed-upon set of goals and prescribed steps to achieve these goals (for review on this perspective see Byrd, et al. 1992). The research within this perspective advocated such techniques as user involvement, highly engineered information requirement analysis methods, and production of prototypes.

\footnotetext{
${ }^{1}$ Here "collaborate" has the original dictionary definition of "working jointly with others or together especially in an intellectual endeavor" (Merriam-Webster's collegiate dictionary, Merriam-Webster, Springfield, Mass., 1998.)
} 
When applied to B2C development settings, these recommendations pose some challenges. For one, consumer-users (users of B2C applications) are typically outside the managerial control of corporations and hence are hard to involve in the design efforts. While in some cases consumers may get involved (von Hippel 1988), for the most part organizations have to rely on market research surveys and customer feedback forms to get users' perspectives on the requirements for a new system. At the same time, applying a well-engineered requirements analysis methodology may be problematic not only because of the lack of user-specified requirements, but also because new entrants into the ISD practice-graphic designers and strategy specialists-may be unfamiliar with these methods. Even within the IS profession, some developers have a hard time learning these tools (Agarwal, et al. 2000). In lieu of requirements engineering techniques, prototyping may become more important (Carlile 2002, Schrage 2000). However, there are well-known problems with prototyping in ISD (Robey and Markus 1984), which may be exacerbated when development work is outsourced and groups with different organizational interests are involved (Terwiesch and Loch 2004).

Over the years, the political perspective has gained prominence in the mainstream IS research outlets (see Sambamurthy and Kirsch 2000 for review) and in the work of the "Scandinavian School" on user-centered design (livari, et al. 1998). The central focus of the political perspective is on the interaction between professional developers and users and among different stakeholders in the user community. Studies found that a large part of these interactions is tainted by power struggles, politics, and interpersonal conflicts (Barki and Hartwick 2001, Newman and Noble 1990, Robey, et al. 1993, Sambamurthy and Kirsch 2000). This literature typically depicts developers as representing management's interests, which are more powerful than the interests of system users (Bødker, et al. 1988, livari, et al. 1998, Orlikowski 1992, Zuboff 1988). However, as organizations start building B2C applications in competitive markets, consumer-users find themselves in a position to choose among multiple competitive offerings. This factor adds an interesting dimension to the power dynamics. Marketing and usability specialists are brought into projects 
to represent users' interests, which may be in conflict with the interests of traditional participants. The users' empowered position also adds an interesting coloring to the well-known conflicts among various business stakeholders trying to exercise control over projects (Kirsch 1996, Markus 1983). It is not clear whether business stakeholders from different groups, such as production, sales, human resources, or corporate strategy, would form alliances among themselves, with technical, or with marketing professionals.

Project participants also have different world views that lead to difficulties in mutual understanding (Davidson 2002, Orlikowski and Gash 1994, Wastell 1999). One key way of negotiating the meaning of the emergent design is through articulation of different viewpoints (Schmidt and Bannon 1992). It is not clear how methods (livari, et al. 1998) used for articulating and negotiating the meaning of the emergent systems, such as the development of design representations (Bødker 1998, Kyng 1995) and use scenarios (Bødker 2000, Jacobson 1993), translate into multi-party settings.

\section{Client-consultant Collaboration in ISD}

With the growth of Information Technology (IT) outsourcing, many ISD efforts include specialized IT service firms participating in projects (Sabherwal and Robey 1993). Consumer-facing applications are especially likely to rely on external help as companies are looking to get quick, often temporary, access to expertise they do not have in-house. One of the critical aspects of collaboration on ISD projects is the mode of control that clients use vis-à-vis consultants (Kirsch, et al. 2002). A recent study of five outsourced ISD projects (Choudhury and Sabherwal 2003) found that the modes of control exercised by clients on outsourced projects differed from those exercised on internal projects. Clients tended to rely more on outcome controls than on behavioral controls at the beginning of outsourced projects, but as time went on, the modes of control shifted towards self-control and behavioral control mechanisms.

As many B2C projects are charged with producing innovative outcomes, the excessive reliance on outcome controls at the beginning of a project may force developers to keep producing quick tangible results, pushing the collaborative process away from the risk-taking needed to develop innovative system 
designs. Also, the greater diversity of participants on such projects, especially such newcomers as graphic designers, may make behavioral control mechanisms impractical as the client may have no expertise in the design methodologies appropriate in these cases. Habitually applying behavioral modes of control to this new domain, for internally or externally sourced projects, may reduce new participants' ability to contribute fully. While outsourcing literature has examined how various modes of control exercised by clients shape the resulting financial outcome and client satisfaction (Choudhury and Sabherwal 2003, Levina and Ross 2003, Sabherwal 1999), it is not yet clear how they shape collaborative practices on ISD projects and emergent designs. Moreover, Gable and Chin (2001) showed that in outsourced projects, client attitudes towards control had low explanatory power, arguing instead that consultants had power to block clients' involvement. This findings support the notion that consultants derive significant power from the use of their specialized expertise (Elkjaer, et al. 1991). It becomes important to understand how clients and consultants simultaneously exercise control over the nature, timing, and outcomes of collaborative efforts.

\section{Collaboration among Developers in ISD}

Studies of software development in organizations examine various formal tools for enabling collaboration among developers. They are often concerned with the problem of "coordination," which is defined as directing individual efforts toward achieving common and explicitly recognized goals (Kraut and Streeter 1995). These studies examine how to coordinate parallel development activities so as to avoid redundancy while maximizing the use of developers' time. Various formalized planning and estimation methods are advocated (Kemerer 1997). Formal project coordination software along with such practices as a nightly "code check" help developers in version control and code re-use (Cusumano and Selby 1995).

While some of these project coordination methods are relevant to coordinating activities with new professional groups entering ISD practice, their work practices and outputs may be hard to fit into traditional coordination tools. Unlike code, modularization of graphic design with subsequent integration of different pieces may lead to unsightly outcomes. Moreover, IS project managers may be unaccustomed to the work 
practices of these professionals and, hence, would have a harder time estimating schedules. Setting aggressive deadlines (Austin 2001), for example, may be detrimental to graphic designers' abilities to exercise their artistic creativity. These challenges may lead to project overruns and tensions.

To conclude, the review of ISD literature leaves us with many open questions when it comes to contemporary ISD settings such as B2C application development. Resolving these questions is important given that coordination of diverse expertise is a critical factor in predicting project outcomes (Faraj and Sproull 2000, Kraut and Streeter 1995). Faraj and Sproull (2000) argue that coordination of diverse expertise is a more important predictor of project effectiveness than traditional factors such as administrative coordination, individual expertise, or development methodologies. A greater diversity among developers is likely to pose additional challenges. For example, Guinan and colleague (1998) find that experience spread among technical professionals has a negative impact on group processes and, subsequently, on project outcomes. In order to manage professionally and organizationally diverse teams, it is critical to understand how project participants negotiate their diversity and how their diversity shapes systems they design.

In what follows, I propose a collaborative reflection-in-action perspective as a useful lens for investigating how project participants collaborate on multi-party ISD projects. This perspective was developed in an inductive, grounded fashion from the case study data and, only then, integrated with existing theories (Glaser and Strauss 1967). Rhetorically, however, I adopt a more didactic strategy.

\section{Collective Reflection-in-Action}

\section{$\underline{\text { Reflection-in-Action }}$}

"Reflection-in-action" is a concept proposed by Schön to understand how individual professionals address uncertain and non-routine, yet repetitive, problems in practice (1983: 60). ISD researchers used this perspective in investigating individual designer's practices (Andersen 1990) and to some extent, the 
user-developer interaction (Bødker 2000, livari, et al. 1998). The reflection-in-action notion helped me understand a situation in which multiple developers interacted as they designed new systems.

Reflection-in-action is a reflective "conversation with the material of a situation" (Schön 1983: 79). Schön notes that "the unique and uncertain situation comes to be understood through the attempt to change it, and changed through the attempt to understand it" (1983: 131). Experimentation does not assume novelty. It is an action taken so as to see and evaluate its outcomes (1983: 145). The process of reflection-in-action cycles through the stages of appreciation, action, and re-appreciation (1983: 132). Appreciation consists of thinking and framing the phenomenon. Action consists of experimentation. A crucial part of re-appreciation is the use of the actor's appreciative systems (perceptions, values, skills) to judge the outcomes of the action and to guide further experiments (1983: 135). Agents struggle over which experiments to preserve for the future from among the experiments that produced the present.

Reflection-in-action is essentially a structurational, practice-based concept (Bourdieu 1977, Giddens 1984). It highlights the duality of structure and action: A designer "shapes" the situation and the situation "talks back" by producing unintended changes, giving the situation a new meaning (Schön 1983: 79, 131). In Schön's view, the "back-talk" can be literal, as in the case of a psychotherapist listening to a patient, or figurative, as when an architect evaluates a drawing that he/she created. In the practice theorybased terms, the present is perceived and the future is created through the lens shaped by the past (Bourdieu and Wacquant 1992).

Although Schön's work is focused primarily on individual practice, he acknowledges the challenges involved in the reflection-in-action of multiple professionals (1983: 204-266). In such case, reflection-inaction involves "on-the-spot surfacing, criticizing, restructuring, and testing of intuitive understandings of experienced phenomenon" (1983: 241). I propose to extend Schön's notion to describe professional practice in collaborative settings that combine diverse expertise. I introduce the term Collective ReflectionIn-Action (CRIA) to describe a "conversation" with different audiences, which brings about dilemmas 
stemming from differences in appreciative systems of participants (1983: 270). In a CRIA cycle, appreciation and action may be undertaken by one agent while re-appreciation and subsequent action is undertaken by another.

There is an important difference between individual and collective reflection-in-action. While individual reflection-in-action often involves silent reflection, CRIA necessitates that participants share objects explicitly, materially (through visible or audible artifacts), thus allowing collaborators to reflect on the results of their colleagues' experiments. The necessity to create material objects to enable collaborative practice is reflected in the notion of a boundary object (Star 1989) prominent in the studies of collaboration.

\section{Boundary Objects}

The notion of "boundary object" has been introduced to describe collaborative problem-solving activities undertaken in scientific communities (Star and Griesemer 1989, Star 1989). It refers to "objects that are plastic enough to adjust to needs and constraints of multiple parties, yet robust enough to maintain a common identity across sites" (1989). In the growing body of literature on boundary objects, the concept has taken different shapes, often physical product prototypes (Bechky 2003, Carlile 2002), design drawings (Bødker 1998), shared IS (Briers and Chua 2001, Pawlowski, et al. 2000), engineering sketches (Bechky 1999, Henderson 1991), standardized reporting forms (Bowker, et al. 1996, Briers and Chua 2001, Carlile 1997, Star and Griesemer 1989) and even shared design factors such as the product yield (Kim and King 2000). The term "boundary object" thus refers to a broad range of artifacts. The founding dual characteristic of boundary objects is their flexibility and robustness. Groups with distinct interests and interests find these objects useful in representing their perspectives (Boland and Tenkasi 1995).

The growing literature on boundary objects has been primarily concerned with classifying their types (Star 1989) and properties (Bechky 2003, Carlile 2002). It has been argued that in order to be both flexible and robust, boundary objects should be tangible (perceived by senses) (Carlile 1997), concrete (addressing specific problems in a specific community) (Bechky 2003, Henderson 1991), accessible and 
up-to-date (Carlile, 1997). They also should help participants represent their differences (Bechky 2003, Carlile 2002). Yet, the issues surrounding the actual use of boundary objects in practice are still underexplored (Schmidt 1997)..

\section{Collective Reflection-in-Action in ISD}

CRIA concept naturally draws our attention to objects in practice because the production, sharing, and use of these objects are necessary conditions for collaboration. By combining the CRIA lens with the insights developed on boundary objects, we may get a better understanding of collaborative practices on ISD projects. Figure 1 offers an illustration of how different agents engaged in collaboration produce, share, and use material objects. While graphically and analytically I depict action as a step that is distinct from reflection, in practice these two steps may happen simultaneously. Figure 1 shows how the process unfolds

over time and uses a circular shape to show a recursive, non-linear nature of this process. Since not all objects produced in multi-party collaborative practice can be viewed as boundary objects (Henderson 1991), the figure refers to objects rather than boundary objects.

The CRIA lens proposed here does not assume that agents come from different backgrounds, nor that they are involved in an ISD practice. To situate this lens in ISD setting, let us consider objects that are produced in such settings, specifically objects that are used to represent the emergent IS design (Bødker 1998). Here I draw on practice theory (Orlikowski 2000) to propose that ISD projects are primarily concerned with designing future IT use practice. And drawing on Orlikowski (2002), I define IT use practice as a recurrent, materially bounded, and situated social action of agents' producing, modifying, and using an IT artifact. These agents include users, future system developers and maintainers, and business stakeholders. ISD participants produce a set of objects (the IT artifact, system documentation, orally expressed ideas, use scenarios, etc.) that help them represent the envisioned IT use practice (Bødker 2000). I refer to the envisioned IT use practice represented through this objects as an emergent IS design. 
There is, of course, plenty of evidence suggesting that the design that emerges from ISD projects is different from the enacted IT use practices (e.g., Orlikowski 2000).

Given the limitations of current views on ISD when it comes to B2C applications, I engaged in an empirical study to examine how developers from diverse backgrounds collaborated on a project and how their collaboration shaped the emergent design. Case study approach was used to understand this socially complex and embedded phenomenon. To understand emergent patterns of CRIA accurately required at least partial reliance on direct observations of practice to record who interacted with whom, when, where, and using which objects. Retrospective accounts and archival data were insufficient for these purposes due to recall biases and the lack of documentation (Barley 1986). I followed an ISD team comprised of diverse professionals from an internet-consulting company (Eserve) and a large division of a publishing company (Pubco) engaged in designing a consumer-based IS².

\section{Research Methods}

\section{$\underline{\text { Sites }}$}

Eserve: In late 1999, Eserve was a young, rapidly-growing professional services firm engaged in end-toend production of B2C applications. Eserve was extremely successful on Wall Street and received a $90 \%$ client satisfaction rating in a third party survey. Historically, Eserve started in the mid-1990s by providing technical web development services. Then strategic consulting expertise was added by hiring management consultants. In mid-1997, responding to competition from design and advertising agencies, Eserve added well-known graphic designers and brand specialists who were attracted by the digital medium, high salaries, and stock options. To integrate "technology," 3 "strategy," and "design" "disciplines," Eserve leaders promoted an egalitarian culture and "open space" environment. Eserve's CEO claimed an ability to integrate different disciplines as Eserve's key competitive advantage:

\footnotetext{
${ }^{2}$ Names of organizations, its members, titles, products, and technology applications have all been disguised.

${ }^{3}$ The quotation marks are used to denote terms used by Eserve and Pubco study participants.
} 
To build digital businesses, to get ideas, and to get them launched in the marketplace you need to put three kinds of people [technologists, strategists, and designers] together in a $12 \times 12$ workspace. Culture is the key-collaboration, sharing, mutual respect. Real innovation is at the intersection of disciplines (excerpt from a public speech).

A critical characteristic of Eserve projects was its three-phase service delivery model: a Planning phase led by strategists with few designers and technologists; a Prototyping phase, which involved more graphic designers and fewer strategists; and a Development phase led and staffed primarily by technologists. The so-called "Waves" service delivery model is captured in Figure 2. The model specified that strategists, who typically played the roles of account managers, project managers, and business analysts, were to interface heavily with clients and make key decisions, while technologists and graphic designers should be primarily involved in tasks associated with building the website. During the business development stage conducted at Eserve's expense, a client would negotiate a fixed fee for each phase contracted separately. While Eserve valued collaboration with the client, its methodology assumed that clients knew little about "the web space" and needed to be heavily "guided" through a series of workshops.

Pubco: In contrast, Pubco was an educational book division of a traditional, multi-divisional publishing company. It had strong hierarchical and departmental distinctions characteristic of the industry (Epstein 2001). Authors and illustrators dealt primarily with the editorial and production staff, while consumers and booksellers were interfacing with the sales and marketing staff. Within the industry, Pubco branded itself as a firm focused more on high quality books than on the sales volume. The IT department at Pubco played only a supporting role and was mostly affiliated with finance and sales groups. Various decentralized webdevelopment teams supported the editorial staff.

Pubco's existing 100+ page website was built by editorial groups without an overarching market or brand strategy. By Fall 1999, Pubco's top executive-under pressure from sales and marketingconcluded that an integrated website that would target a wider audience of consumers and enhance Pubco's brand was necessary. There was both a sense of competitive necessity and of an emerging opportunity to put up a good website quickly. In the words of Pubco's CEO, Pubco had "hit a web wall." In 
September of 1999 Pubco started looking for a partner for the project, eventually picking Eserve. The project officially started in mid-January of 2000 and involved outlining Pubco's web strategy, redesigning the old and developing a new web functionality and look, and implementing the site.

\section{Data Collection and Analysis}

As a setting that combined developers and business stakeholders with diverse backgrounds, the Eserve-Pubco project provided a great opportunity for understanding multi-party collaboration practices in ISD. Starting in January of 2000 , I conducted an eight-month long field study of the Eserve-Pubco project using primarily qualitative data collection techniques (Agar 1980, Barley 1990, Schwartzman 1993, Van Maanen 1979). I negotiated my entry into the project on Eserve's side after observing Eserve's new employee training program. As a non-participant observer, I spent four to five days a week, six hours a day, in different settings at Eserve and Pubco, resulting in 20 to 40 pages of typewritten notes a day. I observed the Eserve-Pubco project every week starting in the second week of the Planning phase and every other week during the Prototyping phase (the other weeks were spent observing a different setting at Eserve). I did not follow the Development phase because my analysis had reached the stage of theoretical saturation, where no new analytical concepts were emerging from data (Glaser and Strauss 1967). I did, however, make several follow-up visits when the application was launched. Day-to-day observations took the form of attending all key project meetings and shadowing specific individuals, primarily at Eserve. While I was slightly limited in my analysis by the lack of daily observations at Pubco, I felt that spending time with Eserve participants allowed me to observe more events directly tied to the evolution of the emergent design.

Detailed observations and document analysis were supplemented with 39 in-depth interviews at Eserve and 21 interviews at Pubco. The interviews were conducted at the end of the Planning phase and again at the end of the Prototyping phase of the project and involved all project participants (see Figure 4 for participants' roles). Those participants who were involved in both phases were interviewed twice. 
Interviews were tape-recorded and transcribed. To incorporate a wider organizational context and the backgrounds of participants into the analysis, I supplemented observational data with data from a Human Resources database, web pages, industry analyst reports, popular press accounts, and financial statements. Critically, I analyzed the project's e-mail, printed documentation, and intranet-based documentation archives. I also took digital pictures of many flip charts, whiteboard drawings, and other objects.

To understand the nature and evolution of collaborative practices and the emergent IS artifact, I employed two analytical techniques: following how emergent designs evolved over time and tracking how power relations among agents shaped their evolution. The first analytical technique was motivated by the boundary objects concept. This analysis focused on understanding how interaction among designers shaped the emergent design. I examined all my notes, interview transcripts, and documents to uncover the chronological evolution of the design from the legacy web-based system to early idea generation, subsequent design choices, and, eventually, the prototype. I treated each new idea about the emergent system as a version of the system design and represented these ideas in a tree-like structure (Miles and Huberman 1984).

In the second analysis, I looked at how the differences in participants' backgrounds and practices exhibited themselves in the enactment of CRIA. To do so, I looked at institutionalized sources of difference such as inter-organizational, professional, departmental, age, gender, ethnicity, education, organizational status, as well as organizational and professional tenure distinctions (Polzer, et al. 2002). While all of these played some role on the project, the inter-organizational and professional differences were most influential in shaping the interaction. I then looked at the data that was not explained by the differences I had considered and uncovered that distinctions based on the degree of project involvement played a key role.

In the Research Results section I first overview key inductive findings from the case, and then present the data and interpret it using inductively developed frameworks. 


\section{Research Results}

My analysis of the Eserve-Pubco project suggests that emergent design ideas expressed in various material objects played a crucial role in enabling collaboration among project-participants. Indeed, the development of the system involved explicating design ideas either through words (intangible artifacts), references to existing artifacts (Pubco's existing website), or development of new artifacts (initiative lists, sitemaps, use case scenarios). However, a careful analysis revealed that the use of these objects enabled some participants, but constrained others (Orlikowski 1992). Moreover, by examining hundreds of objects used on the project, I concluded that whether an object was used at all and whether its use enabled or constrained certain collaborative practices and outcomes, could not be understood through the stable properties of the object (such as tangibility, concreteness, and accessibility), but only through the use of the object in practice.

The use of an object in practice could be conceptualized by classifying different modes of CRIA enacted by participants. Three modes of CRIA could be distinguished from the data: ignoring, adding, and challenging (see Figure 3). The "ignoring" mode refers to a situation in which an object produced as a result of Agent A's experimenting with the emergent design is not reflected upon (ignored) in Agent B's subsequent experimentation with the emergent design. "Reflection" here refers to Agent B making sense of an object in the context of Agent B's practices. Ignoring may happen as a result of not receiving or mentally registering an object or not making sense of it. The "adding" mode refers to an object produced as a result of Agent A's experiment with the emergent design being reflected upon by Agent B and preserved in her subsequent experimentation. Finally, the "challenging" mode refers to Agent B reflecting on the object produced by Agent A and producing an object that does not preserve (transforms) some part of the emergent design produced by Agent A in Agent B's subsequent experimentation. Participants sometimes referred to this mode of work as "undoing". These three modes are mutually exclusive and exhaustive: If an 
object is reflected upon, then a professional's appreciative system changes and this change affects subsequent experimentation, which can either preserve or transform the emergent design.

The next iteration of the analysis revealed how collaboration was shaped by the diversity of agents' backgrounds. Distinctions among agents led to differential power positions on the project. Which mode of CRIA was enacted depended on agents' embedded power relations. Depending on a situation, their organizational, professional, and project involvement-based relations shaped their actions and, in turn, were shaped by their actions.

Following is an overview of the evolution of the Eserve-Pubco project using some examples of objects that were produced and shared by participants. I will describe what happened on the project and follow that with a brief analysis using the concepts that I have just introduced. Then I will present the analysis of how different kinds of embedded power relations shaped and were shaped by different modes CRIA. Due to space limitations, technologists' role in the project will be skipped (see Levina 2001 for a more detailed account).

\section{Business Development Phase}

The first time I ever heard about the Pubco project was from Eserve's account manager who was telling another Eserve employee (Eserver) about his plans to "revolutionize" the publishing industry through this project. This conversation took place at Eserve in early January and followed a lengthy business development phase. Four months earlier, Pubco started looking for an internet consulting firm to revamp its website, which comprised over a hundred pages with inconsistent styles, poor use statistics, and often no references to Pubco's brand.

We really innately do not understand the web, and I think we are trying to figure out how we can participate in this new environment quickly. Of course, we are also trying to figure out how we would make money on it, but that part is not yet evident (one of Pubco's executives, interview).

There were many factors in Pubco's decision to select Eserve, among them was that the sales meeting involved a senior Eserve strategy consultant, experienced in Eserve methodologies and in Pubco's 
industry, who reviewed Pubco's and its competitors' existing web offerings, and proposed several creative ideas that impressed Pubco's management. Eservers also emphasized Eserve's credentials in brand strategy and graphic design, which Pubco's participants hoped would result in a consistent and userfriendly web offering. Early stages of the relationship ended up with a vision in which Eserve would thoroughly redesign Pubco's existing website and build upon it new innovative components and accompanying marketing strategies. This vision was depicted in a slide presentation given by the senior strategy consultant to Pubco's top managers. To accomplish this vision, Pubco's managers shared with Eservers documents that described Pubco's current strategic and technological initiative.

However, as project negotiations continued, Pubco became unwilling to spend the amount of money that Eserve customarily charged for assembling a team of top-notch professionals. The senior strategy consultant was then assigned to a different project, and, in the final proposal (statement of work) signed by representatives of both organizations, the project was scaled down to a comprehensive website redesign with the relatively modest strategic goal of addressing an underserved group of consumers. The Planning phase was shortened to six instead of the usual nine to twelve weeks. And despite these changes, Pubco's top managers reported that although they could not spend as much as some of Eserve's other clients, for the money they were spending, they were expecting to get Eserve's best consultants and see innovative outcomes. They proposed to re-use as much of Pubco's prior strategy and webdevelopment work as possible to help achieve that. This approach was atypical for Eserve projects, which in the early days of the web focused on developing brand new applications.

Eserve's branch manager put together a team consisting mostly of junior strategy consultants with little experience, a half-time senior brand specialist, a half-time senior technology consultant, and a junior technology consultant. Although, Eserve promised all of its clients that $60 \%$ of their teams would have people with more than six months of Eserve experience, at the time Eserve's corporate growth rate made this challenging. The Pubco project was staffed with only $23 \%$ of Eserve-experienced consultants. Pubco's 
top executive hand-picked a "core team" of seven mid-level Pubco managers, a Finance VP as a project sponsor, and a market research consultant as a project manager. Figure 4 depicts each team's composition as the project progressed. Based on personnel records, the people engaged on the two teams were quite different. Compared to Pubco's participants, Eservers were younger (average age of 30 as opposed to 44), had a higher proportion of males (6 males and 2 females at Eserve compared to 2 males and 7 females at Pubco), and were generally better compensated than Pubco participants ${ }^{4}$.

Despite initial enthusiasm, Pubco approached the new project, which was about to cost $6 \%$ of Pubco's operating income, cautiously.

I tried to make it clear to Eserve that if they do not get an understanding quickly of who we are and how we do business, they would fail just like other consultants with whom we had worked had failed (Pubco executive, interview).

\section{CRIA Interpretation}

Before the Planning phase officially started, Pubco participants had an expectation that Eservers would both reflect on Pubco's prior work and use it as a basis for generating innovative design ideas. They encouraged Eservers to collect and analyze their documents, observe their practices, and share Eserve's emergent design ideas to get Pubco's feedback. In other words, Pubco participants expected that Eservers would continuously engage in the challenging mode of CRIA with the objects that Pubco had and would continue to produce. The sales presentation was the first emergent design produced in such a way. It was by all accounts an effective boundary object in that it suited Pubco's and Eserver's needs, it was concrete (it referred to the problem at stake), tangible, and accessible to other project participants (printouts were made for all participants). The use of visual language helped make key points.

\section{Planning Phase}

Before I started observing the project a week after the Planning phase began, I met with Eserve's project manager (Planning PM) at a company party at the home of Eserve's CEO. He was excited about

\footnotetext{
${ }^{4}$ According to the U.S. Bureau of Labor Statistics (www.bls.gov/oes), the mean annual salary in the Computer Systems Design industry was 65\% higher than in the Publishing Industry totaled across occupations.
} 
my joining the project since he perceived the relationship with the client to be strained. He welcomed the opportunity to reflect on the relationship as a result of my participation. He was particularly struggling with the client's project manager (Pubco PM) who was insisting on a lot of seemingly unnecessary documentation that reflected Eserve's comprehension of Pubco's processes and prior work results. As I started observing day-to-day events directly, it became clear to me that Pubco was suspicious of Eserve's ability to deliver. Much of the learning about Pubco's business, which some Eservers had accomplished during the business development phase, was lost when the Planning PM and several new consultants were brought on the project (see Figure 4):

Excerpt from field notes, 02-01-2000 (week 2 of the project: I am following a project newcomer-an Eserve strategy consultant who has just joined in the Planning phase):

Planning PM [after a meeting at Pubco]: They want us to do a lot of prep before we go into a meeting with them. That would be hard to balance because after we do prep and talk to somebody, they also want us to do more. ... Newcomer Strategy Consultant: Do we have notes from the sales meeting?

Strategy consultant who was involved in Business Development: Isn't it in this folder [points to the folder on his desk]?

Later in the day, the newcomer strategy consultant is explaining to me that she is going to work more on the interview guide [for interviewing Pubco's unit managers]. I asked if she plans to read the documents from the pile [pointing to the documents from business development phase]. She said she would take them home with her. She said that she has to be done with the interview guide today to send it to Clare [a manager at Pubco], "whoever she is." She said that reading the documents might influence the interview guide, but that that's Okay [implying that she would send the guide without reading the documents].

The push toward conducting client interviews came from applying Eserve's project delivery methodology, which was developed with the assumption of a longer Planning phase. With the focus always on next steps according to the methodology, the new Eserve consultants did not allocate time to internalizing existing work. As the Pubco participant commented:

I was continuously disappointed in organizational things, the ability to connect the work, the documents that were given to them [Eservers], for example, with the work that comes out... We made a point and spent some time on developing a list of interviewees [within Pubco] - people they should talk to at the beginning of the project. It seems like that got thrown away. ... No interview write-ups [for interviews with business stakeholders that took place], no analysis of past projects, and documentation of having read them. And four weeks into the project, we discovered that they had lost a copy of the strategic plan we gave them. So, we gave them another one. Well, that was just sort of a little shocking to us (interview).

The Pubco PM insisted that her team members be involved in Eserve's processes, and so they participated in the Eserve "branding" workshop with materials critiquing Pubco's web-site. A large 
conference room's walls were papered with printouts of Pubco's current web pages that seemingly had little commonality except that they were about books. Some did not even mention the company's name. Next to those were printouts from competitors' websites. Eserve team members expected that their clients would react to the apparent criticism and that the workshop would generate hours of debate. Instead, Pubco participants were merely expecting a solution:

And I remember at that meeting just trying to say, "Yeah, we are with you. We agree we need to do this to our site. So, what is next?" Instead it was like, I almost felt like, at that meeting they were ready for us to really fight that. And once we agreed like, "Yes, we are with you. We have to change," they did not know where to go (Pubco's core team member, interview).

To try and save the situation, an Eserve consultant proposed that all workshop participants use sticky notes to provide comments on Pubco's and competitors' designs and then try to identify what makes for a good publishing website design. The comments made in the workshop were well-documented in meeting notes, but there was no further reference made to them. Based on my observations, there was no further thought given to the existing website until the beginning of the Prototyping phase six weeks later.

Toward the middle of the third week of the Planning phase, when, according to the Eserve service delivery model, consultants should be up-to-speed with the client's business, Eserve was scheduled to conduct a brainstorming workshop. By that time, Eserve's PM and account manager had decided that the clients were afraid to speak their mind due to internal politics and were not engaged in generating solutions, were "culturally stubborn," and "process obsessed." However, they wanted to participate and needed "pieces of paper" to signify success. Some Eservers warned that "we should not stereotype" or "they will question our methodology," but their voices did not resonate with the rest of the team. It was concluded that the main objective for the meeting was to make clients feel "that they had contributed."

At the end of the brainstorming session, Pubco participants generated more than a hundred ideas (initiatives) for what the site functionality should be. Eservers primarily facilitated or observed the workshop. The next major step of the Planning phase was a prioritization workshop, which involved Eservers scoring initiatives on multiple dimensions. The entire fourth week of the project was allocated to this exercise. First, 
clients were supposed to rank the relative importance of fifteen criteria used by Eserve for ranking (e.g., "strategic impact" and "technical feasibility"). Then Eservers were to rank all the hundred plus initiatives generated in the brainstorming session based on each of the newly-ranked criteria. For each criterion, consultants were to support their judgment with research including user's perspective, competitive analysis, and a technological assessment of the client's capabilities. Then all the ratings were to be put through a complicated and automated reduction algorithm that would "spew out" nice reports indicating which initiatives to pursue. Clients could then provide their feedback and choose the top initiative to implement.

It was during this fourth week, halfway through the Planning phase of the project that something happened. Still lacking an understanding of what the Eserve service delivery model was about and suspicious of Eserve's methods, some of the key Pubco people from sales and marketing started worrying that initiatives which they believed to be essential were not prominent on the Eserve's list. The Pubco PM conducted two Pubco-only workshops where core team members identified and prioritized their "critical" initiatives under the heading of "key elements of our web presence that we know we need to develop for our core business." This "must have" list was relayed to Eserve's project manager at a meeting at Pubco and sent by the Pubco PM to the Eserve team to be included with the previously brainstormed initiatives:

Excerpt from field notes, 2-15-00 (I am attending a meeting at Pubco) Pubco PM [addressing Planning PM]: We don't have a lot of functionality that we absolutely need. We are not trying to stop the process. We are trying to make sure that you [Eserve] know these are the things we are going to be looking for quickly. ... If we put it through our prioritization matrix, we will end up with them.

Meanwhile, Eserve consultants started picking up steam. They sought guidance from senior strategy experts, analyzed Pubco's existing technology initiatives, and interviewed a dozen of Pubco's customers (potential and current users). At the same time, one conscientious new Eserver worried that the Eserve team was not holding its own brainstorming session. This consultant convinced Eserve's PM of the necessity of internal brainstorming in order to deliver "high-quality," "truly innovative" Eserve results. Eservers did hold a short session and generated initiatives that were significantly different from the client's "must have" list. In generating their ideas, Eservers drew on their own experience in implementing web- 
based initiatives in other industries and their interaction with Pubco participants. They also drew on insights gained from a dozen of the user interviews conducted by an Eserve strategist, which Pubco participants had dismissed arguing that the sample size was too low. However, they also received the "must have" list from the client. To save the relationship and get funding for the Prototyping phase, Eserve strategists decided that this client was too traditional to handle "out there" initiatives and that it would be best to proceed in a "consulting as usual" approach. This, according to Eservers with experience in traditional consulting firms, included pleasing the clients and "throwing tangibles" at them to show that they were "getting their money's worth." While Eservers also presented the initiatives that they had generated on their own, they mainly recommended those that had been proposed by Pubco, and used a sophisticated analysis methodology to justify their recommendations. In my interviews, several Pubco's core team members expressed disappointment with the outcome of the meeting:

In some ways these are ideas [initiatives that were ultimately chosen] that a bunch of people here and I have had for a while, but you have to hire a consultant and pay them a lot of money to make sure that the ideas are comfortable to everybody. ... And now they [Eserve] are only listening and not pushing back. I have never felt like they really pushed at us. Well, you know, that is hard. Maybe, I am having a hard time evaluating them now, maybe they pushed and I just did not like it, you know. I do not know. Um, when you push someone, you need to provide, you know, another way of ... an alternative (Pubco's core team member from the sales and marketing function, interview).

Indeed, by the end of this phase, others at Pubco seemed comfortable with the proposed ideas. One of the things that Pubco's top executive found particularly helpful in understanding and supporting the proposal was a graphic depiction of a potential user engaging with the proposed website's features to evaluate and choose Pubco's products. Eservers referred to this use scenario as Day In the Life Of (DILO) a user. It was introduced into Eserve's methodology by their marketing gurus, but was developed here by the Planning PM. The DILO was seen as so helpful that Pubco's top executive took it to an executive retreat to share with leaders of other divisions:

I think what Eserve brought to it is a way of communicating these very complex issues in a specific or applied way as opposed to just in a theoretical way. You can talk to me until you are blue in the face about communities or about business to business on the web or whatever, but they did a fabulous job of taking all the things we have been working on and laying them out in this sort of diagrammatic way (interview).

Looking back at the Planning phase of the project, she continued: 
I think everyone always felt Eserve people were smart, but we were not always getting the feedback, or even understanding anything we were talking about, or internalizing it, using it, and then forming their opinions or judgments. So, something happened along week three and a half or four that turned this around.

\section{CRIA Interpretation}

While the presentation made by Eserve's senior strategy consultant in the business development phase was available to all participants, it was not used by Eservers in subsequent phases of the project. Moreover, in the first three weeks of the Planning phase, Eservers generally ignored emergent designs previously produced by Pubco. This was especially evident in the interview guide (objects) that Eservers used for interviewing unit managers at Pubco-a point of frustration that was stated in every interview I conducted at Pubco. Eservers did, however, use Pubco's and its competitors' existing websites as a basis for experimentation in the branding workshop, enacting the challenging mode of CRIA. Yet, subsequently, emergent designs represented in a set of sticky notes and with comments attached to webpage printouts were ignored. Again, this very concrete, tangible, and accessible object was never used. This was also the fate of many of the hundred-plus initiatives that were generated in the brainstorming workshop. First, Eservers enacted the adding mode of CRIA by consolidating initiatives into themes and ranking them based on various criteria. Eservers' then challenged these emergent designs when they brainstormed their own ideas. Next, however, Pubco's "must have" list was produced by ignoring all the objects produced after the brainstorming workshop. Eservers then discussed the choice of whether to openly engage in challenging Pubco by prioritizing Pubco's "must have" list lower than some of the other initiatives or whether to accept the list by adding a fancy justification to it. The latter option was chosen. The DILO object was produced as a result of adding graphics to make the emergent design easier to comprehend. As a use scenario, DILO possessed all the properties of an effective boundary object (Bødker 1998).

\section{Prototyping Phase}

In the Prototyping phase, following Eserve's "Waves" model, three new design "discipline" members (two junior graphic designers and an information architect) and one senior technologist joined the 
team. It was expected that the designers would help deliver the graphic treatments for the website mockup-a click-through prototype with minimal functionality. Another major change in this phase was the arrival of a new project manager (henceforth "Prototyping PM"), who had extensive B2C project management experience. Also, after much discussion among the managers on both sides, it was decided that to improve Eserve-Pubco communications it was best to divide the work into three smaller EservePubco integrated sub-teams (requirements, design, and technology). The Prototyping PM and Pubco PM would attend meetings of each sub-team as liaisons. Figure 4 lists participants in this phase.

When the new members officially joined the team, they were given copies of the final deliverable from the Planning phase to read. In a "knowledge dump" meeting, the Planning phase strategists walked the newcomers through the deliverables deck, which contained the DILO. In addition, the newcomers were all encouraged to browse the existing Pubco site. The designers, who did not know the publishing industry well, had difficulty understanding the DILO's or existing websites' terminology. However, the Prototyping PM, who was continuously interacting with Pubco participants in various meetings increasingly started to understand Pubco's language, while the designers were still lost.

As the Prototyping PM started understanding Pubco's business, she started questioning "the strategic value" of the initiatives proposed in the Planning phase in her conversations with Pubco's core team members. She proposed that project participants go back to generating and prioritizing initiatives. However, Pubco and Eserve Planning phase participants explained to her that she did not know the history behind the selection of the initiatives. Subsequently, Pubco's project leaders complained to the Prototyping PM's superiors about her lack of professionalism.

Meanwhile, Eserve strategists and three non-technical Pubco managers assigned to the requirements sub-team were engaged in building "use cases." Use case scenarios are part of the UML (Universal Modeling Language) object-oriented systems analysis methodology and typically rely on graphic representations of users' and systems' actions (e.g., Jacobson 1993). However, Eserve strategists were 
not familiar with UML so they decided to create use cases in the form of traditional functional requirements captured as hierarchical bullet lists in a word processor. Eservers produced initial documents based on their market research (e.g., what Amazon has done), Planning phase documents, and Pubco's current website. Then, members from both organizations discussed and debated the documents in meetings.

Once use case documents were finalized, they were passed on to Eserve graphic designers to develop the mockup and the information architect to produce a new site map. Hours and eventually weeks were spent in meetings with designers who were still not "getting it." Eserve strategists were growing increasingly frustrated that the designers were not "taking ownership" of the website and were not "making an effort to learn." At that stage, designers were only able to produce a color palette and a font guide based on their review of Pubco's current website, but not a single web page design. It seemed that the only object that they "did get" was a graphical depiction of the sitemap for the existing website. Interestingly, Eserve strategy consultants initially argued against producing this sitemap saying that Eservers should start from scratch to avoid repeating poor design mistakes made by Pubco. Yet, the Prototyping PM insisted that the sitemap be produced and all the designers and strategists reported in interviews that this document was the most helpful tool in their communication. However, despite the sitemap's usefulness, graphic designers still did not know which information to put on the new index page and the information architect was unable to produce a new sitemap.

Towards the midpoint of this phase, with deadlines coming and going one after another, the Prototyping PM started reflecting on the approach that was being taken for communicating with designers. Through a number of contentious conversations with designers, where much frustration was expressed and even tears were shed, the Prototyping PM realized that the designers were not accustomed to working with structured documents and were not using what was sent via e-mail or handed out. One of them openly admitted in a meeting that he had no inclination to learn to read structured documents and disposed of use case printouts. The others admitted trying to comprehend, but then giving up: 
I was looking at them [use cases] but I could not understand them. I would read through them, but it seemed like they were not making sense, and it just kept on ... they [the requirements sub-team] were sending out a lot of documents (a designer, interview)

Dissatisfied with designers' unwillingness to learn the strategists' tools, the Prototyping PM asked strategists to build first-cut wire frames, black and white schematics of web pages with no graphics, and give these to designers. Although strategists supported this decision, they felt that they were doing the work that was not their responsibility. They expressed frustration at seeing designers go home at $6 \mathrm{pm}$ and take weekends off while strategists had to stay, sometimes until 3am, to finish the wire frames. However, as soon as the designers got the first wire frame from strategists, they were up and running—working long hours like the strategists and producing results. The information architect started using the navigational choices made by strategists in wire frames to reconstruct a sitemap for the new website. Designers were able to deliver several graphic treatments for the index page in a few days, and the project finally moved forward after a month-long delay and only three weeks before the delivery date. Pubco core team members liked one of the designs and it was selected to set the style for the rest of the mockup.

Initially, graphic designers told strategists that for ease of use and aesthetic appeal, the top-level navigation should have three to five navigation elements and no more, which is what strategists followed in the first set of wire frames that they produced. However, as wire frames were discussed with Pubco participants, new understandings of Pubco's priorities were realized, leading to some changes to the index page navigation. Instead of three navigational elements, the index page now included six. Later, when a seventh navigational element was added, one of the designers wrote in an e-mail to the group, "Speak now or forever hold your peace." A number of other links did not fit into the current design, and designers had to change the design to accommodate them. For example, they had to "harden the edges" (make the banner and graphics look more square) and decrease the font sizes. When an eighth top level navigational element was decided upon, the designers lost almost all of their "soft edges." With a week left until the 
delivery date, designers did not argue. "There was no time and the strategists did not want to talk to us," one designer explained in an interview.

Subsequent pages were designed in a similar manner. Strategists produced wire frames and designers added colors and graphics on top of them. One of the designers reflected on the process:

It helped getting wire frame forms. It-that process,-even though it was like an assembly line like, it, you know, it helped as far as efficiency went. But it did not [pauses]. I was not understanding the basis behind it. ... I just remember thinking that if I had had the information [about what goes on a webpage] to begin with and had organized it, I definitely would have arranged it differently (a designer, interview).

Pubco participants found wire frames very helpful:

I cannot even imagine how you talk about what is going to be on screen without using wire frames, you know. I have got to use them. (Pubco requirements sub-team member, interview).

At the end of the Prototyping phase, however, neither Eservers nor Pubco participants particularly liked the outcome.

The design? I'm pretty happy with it. But I do feel that it got watered down. Too many people...they were trying to accommodate all these different suggestions and comments and we've lost a bit of the originality of the original design. I actually prefer the very original. I really liked the light colors. I thought it was very sophisticated and soft (Pubco's technical manager, design sub-team member, interview).

The strategists blamed the designers for not learning well enough, not working hard enough, and not providing "creative input" into the wire frames. The Prototyping PM raised a performance issue with the designers' mentors at Eserve. The usability test conducted on phase completion indicated what designers knew all along-there were just too many main navigational elements that were decreasing the usability and aesthetic appeal of the site. Pubco decided to invest money into three more weeks of mockup redesign guided by experienced designers. Because the full mockup design was still not done, the Development phase, which lasted twice as long as planned (six instead of three months), included seven representatives of the design discipline for the first two months-instead of Eserve's usual two participating in that phase. In the implemented website there were just four top level navigational elements and plenty of soft edges.

\section{CRIA Interpretation}


The DILO document was supposed to be the boundary object par excellence in facilitating collaboration among strategists and graphic designers. It related directly to graphic designers' practice by using a simple visual language. It was also concrete in the sense that it addressed the problem at handthe emergent website design (Bechky 2003). It was accessible and up-to-date. However, it was not used for reflection by graphic designers, who eventually ignored it and stagnated in their work until wire frames were produced by strategists. Wire frames and the sitemap were actually the best boundary objects in the Prototyping phase in that they were used for reflection by all the key parties involved. Eserve strategists and Pubco participants produced these objects by reflecting on and challenging emergent designs captured in use cases, the DILO, the existing website and its sitemap. They also went through several iterations of wire frames again by engaging in the challenging mode of CRIA. The adding mode of CRIA that designers enacted in their production of graphic treatments and the new sitemap on the basis of wire frames was disappointing to everybody.

\section{Power Relations Analysis}

While many project participants could upon reflection differentiate their enactment of ignoring, challenging, or adding modes of CRIA, it was not then apparent to them or to me why certain design alternatives were being ignored, while others were reflected upon, and then either added to or challenged. An answer to this question was in an understanding of how an emergent design was shaped by diverse practices of project participants. The diverse practices of participants were used to distinguish one group from another and served as a basis for exerting influence over the emergent design (Bourdieu and Wacquant 1992). Adding to the work of another resulted in preserving this party's expertise in the emergent design; whereas, challenging or even ignoring it transformed the emergent design. Whose expertise got preserved in the emergent design was at stake for agents involved (individuals, groups, and organizations) as they could or could not claim credit for or take ownership of it. Agents used their expertise and control over resources in enacting different modes of CRIA. 
On Eserve-Pubco project, organization, profession, and project involvement-based distinctions gave rise to power relations which shaped CRIA. While other types of power relations based on social distinctions associated with hierarchical status, organizational tenure, age, gender, and educational background also played a role, my data analysis indicated that the three discussed below were most critical.

\section{Client-Consultant Relations}

There is a well-known tension on consulting projects between clients, who bring their economic resources, and consultants, who bring their expertise (Yakura 1993). Many authors emphasize the ethical responsibility of professional consultants against abusing the power that they derive from having an expertise basis unfamiliar to clients (Elkjaer, et al. 1991, Schön 1983, Yakura 1993). However, when a client has an opportunity to withdraw economic resources in a contract, it also possesses a significant base of power. Clients also use their own expertise as a basis of power in accepting or rejecting advice or controlling consultants' processes (Kirsch, et al. 2002). Consultants, in turn, have economic levers as they decide on the level of investment they will make in a particular client's project (Hart 1995).

When Eservers enacted the challenging mode of CRIA when pitching their proposal to Pubco, their actions were produced on the basis of a symmetrical power relation-an ideal promoted by the social studies of consulting work (Czarniawska and Mazza 2003). The enactment of the challenging mode reflected Eserve's giving proper consideration to Pubco's competence in the publishing industry and using its own web-based strategy and design expertise. When Pubco signed a narrowed-down contract stating that Eserve should rely on Pubco's strategic documents to save money, it ignored Eserve's expertise in the web strategy space by offering to substitute its own. Eserve then staffed the project with junior strategy consultants and shortened its duration. However, Eserve's institutionalized practices positioned Eserve as an authority in generating innovative web-based initiatives. Ignoring most of Pubco's prior work was not simply the result of lack of time, but rather the result of strategic forgetting (Bowker 1997) which prioritized 
"the Eserve way" of doing things over reflecting on the client's input. Pubco's development of the "must have" list as a result of ignoring Eserve's current work was a reinstatement of Pubco's authority as an expert in web strategy for the publishing industry. Eserve accepted Pubco's relative dominance by adding fancy justifications to the "must have" list, to a large degree because the contract structure allowed Pubco to threaten the exercise of its economic power by withdrawing funding in the next phase.

Project participants preserved web strategy decisions made in the Planning phase in the subsequent cycles of CRIA. The emergent design that was ultimately delivered reflected strategies preconceived by Pubco's sales and marketing managers. This, in turn, re-shaped these managers' relative power positions within Pubco as they used the Eserve-Pubco project to help implement a long-desired process change within Pubco, which improved technology product consistency in editorial departments.

\section{Professional Relations}

Designers were latecomers to Eserve. They did not serve in any top management positions and there were only a handful of them among account managers. When they joined the firm, many Eserve methods had been well-established through repeated enactment and official documents (Bourdieu and Wacquant 1992). Such practices as documenting emergent designs in a structured way and delivering results of incremental progress to clients were staples of management consulting practices, but did not fit a designers' way of working. Not only were many designers unaccustomed to working with structured requirement documents, but their work was also highly non-linear. Designers could go for days without producing anything while waiting for creative inspiration. Their training also encourages them to evolve several designs at a time knowing that only one would be implemented. Moreover, Eserve's three-phase "Waves" model excluded designers from many early decisions made about the site, thus limiting their ability to influence the emergent design. It also removed designers from much of the client relationship, which strategists used as a source of power. In short, Eserve's project delivery practices institutionalized the designers' "followers" role. Although some designers recognized this inequity and even advised job 
candidates to seek design jobs elsewhere, they were not inclined to change the situation, arguing in interviews that it was hopeless to consider doing so.

On the Eserve-Pubco project, the designers' disadvantageous position led to the repeated enactment of the adding mode of CRIA. Despite wire frames appearing flexible enough to adjust to designers' needs (Star 1989), designers never felt empowered enough to challenge strategists' expertise. In the CRIA cycle that emerged, joint product stakes, such as the amount of functionality over aesthetics, were attained by the strategists time after time. Also, the designers' reliance on strategists for wire frames allowed strategists to claim credit for working extra hard and "pulling the project through." Designers were all replaced in the next phase of the project and could not claim credit for the site in their portfolios (a significant loss to their careers).

Why did designers not invest in learning how to utilize structured requirement documents such as use cases to take control? Such an investment, which involved understanding and accepting linear thinking in generating emergent designs, was intricately tied to the change in their professional identities. What they knew and did defined who they were (Van Maanen and Barley 1984). In fact, ignoring use cases was a reaffirmation of designers' professional identities. A few designers, who had been with Eserve for a while, did learn the strategists' way of practicing and moved into project leadership positions. They also stopped practicing hands-on graphic design and focused on managing.

\section{Project Involvement-based Relations}

Although much of the work on diversity in organizations focuses on professional, organizational, educational, gender, race, age, and hierarchical diversity (Guinan, et al. 1998, Polzer, et al. 2002, Reagans and Zuckerman 2001), distinctions demarcated by different degrees of involvement in the project at hand are often overlooked. Yet, on the Eserve-Pubco project, power relations based on this distinction played a crucial role. Newcomers to the project found themselves in disadvantageous positions vis-à-vis those who were involved earlier on. For example, when new strategy consultants joined the Planning phase, their 
ability to influence the emergent design was limited as they did not know what had transpired on the project before. Clients' perception of them, which was a source of power for other strategists, was less favorable.

Much like designers ignoring the use cases, newcomer strategists' disregard for objects produced before the Planning phase was a reaffirmation of their authority in producing an emergent design. If the new design produced "from scratch" is preserved in subsequent modes of CRIA, newcomers could effectively restart the clock on the project and gain an advantage in relation to other project participants. Planning phase newcomers succeeded in ignoring what Eserve consultants produced before they joined and eventually played a central role on the project. However, the Prototyping PM, who challenged Planning phase results, was less successful. Her action led to her diminished status on the project.

The most striking example of the effect the project involvement-based power relations had on the CRIA enactment was the designers' inability to use the DILO object. The lack of expertise in terminology and business logic used in the DILO led designers to ignore this seemingly perfect boundary object. Other objects that project old-timers produced for them, including verbal explanations from the half-time brand specialist involved in the Prototyping phase were also ignored (not made sense of). Designers were only able to make sense of wire frames, which for them represented the skeleton of a generic graphic design, and not any Eserve-Pubco project-specific content. Inability to "get involved in the project" cost them dearly.

\section{Discussion}

To address the first research question, I drew on field study data and Schön's theorizing about professional practice to argue that multi-party collaboration on ISD projects can be understood as a CRIA cycle. The cycle is enacted through the sharing of material objects, often referred to as boundary objects in organizational literature. Schön argued that the real question is "not so much whether to reflect as what kind of reflection is most likely to help us" (1983: 280, original emphasis). My analysis identified three different modes of the enactment of this cycle: ignoring, adding, and challenging. Usefulness of a particular object in collaborative practice was not a property of the object per se, but was associated with ways in 
which the object was used. The IS design emerged through the enactment of CRIA which either preserved or transformed contributions to the design made by individual agents. In addressing the second research question, I argued that the diversity in participants' backgrounds exhibited itself in collaborative practice by forming different bases of power. Multiple overlapping power relations shaped which mode of CRIA was enacted. In addition to the inter-organizational and professional power relations, recognizing project involvement-based power relations provided unique insights into agents' action. At the same time, the kind of experimentation that took place, and whether it was preserved in time, was at stake for the agents. When agents attain these stakes their power relations change. Figure 5 provides an illustration.

To arrive at these conclusions I made some critical theoretical and methodological choices. My data collection methods privileged an in-depth understanding of one specific case over a broader understanding of multiple cases. This choice was made because the phenomenon of interest (collaboration) unfolds through day-to-day interactions among ISD participants, is not fully understood by participants, and is important to study longitudinally. The specific practices that are described in this paper cannot be generalized beyond the Eserve-Pubco project, even to other Eserve projects. However, theoretical constructs such as CRIA, its modes, and the factors that shaped it and are shaped by it could be usefully applied to other settings (Lee and Baskerville 2003). While readers familiar with ISD and consulting practice may argue that the dynamics of the project can be explained by Eserve's poor project management skills, consultants' lack of experience, or by political interests and manipulative moves of certain groups within Pubco, these explanations offer limited insights into collaborative dynamics on an ISD project. For example, the Prototyping PM by many accounts was an excellent project manager, but the project was not delivered on time nor did it fully satisfy its stated objectives. More importantly, the concepts developed here can help us understand what is meant by good project management or consulting skills. 


\section{Implications}

A persistent conclusion in IS literature is that more in-depth studies of ISD processes are needed to achieve a richer understanding of this complex social phenomenon (Newman and Robey 1992, Robey 1994, Sambamurthy and Kirsch 2000). I took this call seriously and developed a new CRIA lens for understanding multi-party collaborative practices in ISD. The new framing offers insights into challenges encountered on $\mathrm{B} 2 \mathrm{C}$ projects as marketing and design professionals enter these settings as representatives of consumer-users' views. Whereas consumer-users have the power of their wallets to give voice to their interests, this study highlighted that marketing and design professionals have a harder time doing so in ISD settings that are dominated by technical and strategy specialists. The time pressure on these projects also exacerbates this challenge as designers tend to work in non-linear ways. The framework developed here provides insights into understanding these challenges for both researchers and practitioners. I will outline implications of this work to the studies of multi-party collaboration in organizations and in contemporary ISD as well as to future research on social processes in ISD.

First, by developing a CRIA lens, I was able to give further support to the notion that material objects play a crucial role in collaborative efforts. Yet, my analysis indicated that focusing on the object itself provided insufficient insight into whether or not an object became a boundary object in practice. Some objects (e.g., DILO), may be particularly well-suited to become boundary objects for a given boundary, but are simply not used by agents, rendering them obsolete. Moreover, the production and use of boundary objects, which are often useful for facilitating communication, may aid or inhibit collaboration depending on the object's use. Indeed, wire frames were very useful in communicating what strategists wanted from designers. Yet, the emergent designs they captured were left unchallenged and inhibited collaboration. While organizational theorists have moved beyond studying physical properties of an object toward understanding its "social properties," such as whether an object represents the differences among groups 
(Bechky 2003, Carlile 2002), my findings suggest that further insights could be gained if research focus shifts from an object to the practices surrounding the use of an object.

Second, this research has important implications for studying diverse teams. The literature on diversity has been traditionally concerned with stable, well-understood kinds of diversity such as demographic, organizational, and functional diversity (Guinan, et al. 1998, Polzer, et al. 2002). The application of the CRIA lens highlights the usefulness of the structurational, practice-based view of diversity, which links diversity with power relations. While initial power relations shaped CRIA, different modes of CRIA shaped power relations. In this dynamic view, different kinds of diversity have different relationships to teams' processes and outcomes depending on the situation. Seeing diversity as emergent rather than static highlighted the importance of the project involvement distinction and associated power relations., Bunderson (2003) found that power centralization in a team was a critical moderator between team members' functional background and intra-team involvement. The CRIA lens can be used to investigate the processes which account for this finding. My analysis also suggests that the relationship is bi-directional: intra-team involvement also influences agents' centrality, as we saw in the case of the strategy consultants. Future research can also address the important question of which sources of diversity become salient at different times and places and why.

Third, the study illuminates the often unspoken, but frequent occurrence of ignoring in collaborative practice. The distinction between the adding and challenging modes of work is not new. In organizational literature, theorists wrote about the trade-offs between "efficiency" and "innovation" or "exploitation" and "exploration" (March 1991). However, organizational theory has not highlighted the third basic mode of joint practice-ignoring. We are well familiar with this mode of practice from our everyday lives. From pieces of junk mail to prior research articles on our topic of interest, we ignore much more than we reflect on. The data shows instances of ignoring associated with being unaware of an object intended for reflection, being unable to physically access it, or lacking a competency necessary to interpret it. However, ignoring also 
occurred when the object was "fully accessible" and interpretable, as was the case with the sales presentation created in the Eserve-Pubco business development phase. Moreover, ignoring should not simply be seen as "dysfunctional." Eserve-Pubco project participants often ignored objects produced by others in order to reaffirm their professional, organizational, or project involvement-based identities. This suggests that research of organizational learning and collaboration should not omit this mode of action from its analysis. In studies of IS implementation, we can build on Bowker's (1997) initial insights on strategic forgetting by considering intentional and unintentional ways in which ignoring occurs.

Beyond these three sets of implications for studying collaboration in general, there are also several specific implications of this work for understanding ISD practice. First, this research indicates that the use of structured analysis and design techniques is problematic as it privileges technical and strategy expertise over design expertise. Researchers and practitioners may benefit from developing new methods of working that take designers' competencies and practices into account. One idea might be to start with the development of graphic treatments before requirements are written down and to allow designers to hypothesize what the functionality even if it made no business sense. Functional analysts can then draw on their expertise in a client's business to challenge these emergent designs by proposing appropriate functionality. This approach would temporarily bifurcate graphic design and requirements analysis work and allow designers more time and freedom to exercise their creativity and professional judgments. Practitioners and methodology designers can also use this analysis to reflect on power structures on projects. For example, Eserve often succeeded in designing usable and functionally rich websites when it put designers in account and project management positions. Also, having designers involved early in critical design decisions can empower them vis-à-vis project involvement-based power relations. Future research can address the question of how different staffing arrangements and patterns of enactment of CRIA shape the emergent designs. 
In terms of managing inter-organizational projects, this study bridges the gap between those researchers who emphasize control exhibited by the clients (Choudhury and Sabherwal 2003, Kirsch, et al. 2002) and those who emphasize control exhibited by consultants (Elkjaer, et al. 1991, Gable and Chin 2001). Moreover, the structurational view of power relations illuminates how different organizations may be controlling the direction of the emergent designs at different points in time, and how different modes of CRIA would influence this power relation. Depending on the clients' and consultants' interests they may pursue more symmetric or asymmetric relations (Czarniawska and Mazza 2003). For example, one of Eserve's top executives said in an interview that she strongly advised the Pubco PM not to exhibit behavioral control over Eserve. Yet, the Pubco PM was uncomfortable with Eserve exercising behavioral control over Pubco by enacting Eserve specific practices and ignoring Pubco's prior work. The CRIA lens can be used to further investigate the evolution of different control mechanisms exercises by both parties on inter-organizational ISD projects (Choudhury and Sabherwal 2003).

To conclude, the CRIA lens helps us further open the black box of ISD, not just to see which social forces and interests influence the emergent design, but also to see how the design emerges through the sharing of material objects produced by participants. An early application of the CRIA lens to ISD practice on individual level can be found in the Professional Work Practice approach (Andersen 1990). This approach has been criticized for seeing ISD as a process of modeling the reality surrounding designers rather than shaping it (livari, et al. 1998). This paper shows how Schön's lens can be fruitfully extended to the analysis of collaborative practices. It also illustrates how actions taken by professional developers and business clients with diverse backgrounds and interests rather than objective realities shape the emergent product. Together the CRIA lens and the analysis of power relations help us understand why ISD participants adopt one or the other mode of practice and produce particular designs. These analytical tools can be usefully applied to other IS development and use settings. For example, projects with direct user involvement would make for an interesting analysis. 


\section{References}

Agar, Michael, The professional stranger: an informal introduction to ethnography, Academic Press, New York, NY, 1980.

Agarwal, R, P De, Ap Sinhaand M Tanniru, "On the usability of OO representations," Communications of the ACM, 43, 10, (2000), 83-9.

Andersen, Niels Erik, Professional systems development : experience, ideas, and action, Prentice Hall, New York, 1990.

Austin, Robert, "The Effects of Time Pressure on Quality in Software Development: An Agency Model," Information Systems Research, 12, 2, (2001), 195-207.

Barki, Henri and Jon Hartwick, "Interpersonal conflict and its management in information system development," MIS Quarterly, 25, 2, (2001), 195.

Barley, S. R., "Technology as an Occasion for Structuring - Evidence from Observations of Ct Scanners and the Social-Order of Radiology Departments," Administrative Science Quarterly, 31, 1, (1986), 78-108.

Barley, S. R., "Images of Imaging: Notes on doing longitudinal field work," Organization Science, 1, 1, (1990), 220 247.

Bechky, Beth, "Sharing Meaning Across Occupational Communities: The Transformation of Understanding on a Product Floor," Organization Science, 14, 3, (2003), 312-330.

Bechky, Beth Allison, "Crossing Occupational Boundaries: Communication and Learning on a Production Floor," unpublished Ph.D. Dissertation, Stanford University, 1999.

Bødker, S., "Understanding representation in design," Human-Computer Interaction, 13, 2, (1998), 107-125.

Bødker, S., "Scenarios in user-centred design - setting the stage for reflection and action," Interacting with Computers, 13, 1, (2000), 61-75.

Bødker, Susanne, Pelle Ehn, Joergen Knudsen, Morten Kyngand Kim Madsen, "Computer support for cooperative design," Proceedings of the Conference on Computer-supported cooperative work, Portland, OR USA, 1988, 377-394.

Boland, Richard J., Jr. and Ramkrishnan V. Tenkasi, "Perspective making and perspective taking in communities of knowing," Organization Science, 6, 4, (1995), 350-372.

Bourdieu, Pierre, Outline of a theory of practice, Cambridge University Press, Cambridge ; New York, 1977.

Bourdieu, Pierre and Loïc J. D. Wacquant, An invitation to reflexive sociology, University of Chicago Press, Chicago, 1992.

Bowker, G., S. Timmermansand S. L. Star, "Infrastructure and Organizational Transformations: Classifying Nurses' Work," In Information Technology and Changes in Organizational Work, W. J. Orlikowski, G. Walsham, M. R. Jones and J. I. DeGross (Ed.), Chapman and Hall, London, UK, 1996, 344-369.

Bowker, Geoffrey, "Lest we Remember: Organizational Forgetting and the Production of Knowledge," Accounting, Management and Information Technologies, 7, 3, (1997), 113-138.

Briers, Michael and Wai Fong Chua, "The role of actor-networks and boundary objects in management accounting change: A field study of an implementation of activity-based costing," Accounting, Organizations and Society, 26, 3, (2001), 237-269.

Bunderson, J. S., "Team member functional background and involvement in management teams: Direct effects and the moderating role of power centralization," Academy of Management Journal, 46, 4, (2003), 458-474.

Byrd, T. A., K. L. Cossickand R. W. Zmud, "A Synthesis of Research on Requirements Analysis and Knowledge Acquisition Techniques," Mis Quarterly, 16, 1, (1992), 117-138.

Carlile, Paul Reuben, "Understanding Knowledge Transformation In Product Development: Making Knowledge Manifest Through Boundary Objects," unpublished Ph.D. Dissertation, University Of Michigan, 1997.

Carlile, Paul Reuben, "A Pragmatic View of Knowledge and Boundaries: Boundary Objects in New Product Development," Organization Science, 13, 4, (2002), 442-455.

Choudhury, Vivek and Rajiv Sabherwal, "Portfolios of Control in Outsourced Software Development Projects," Information Systems Research, 14, 2, (2003), 291-314.

Cusumano, Michael A. and Richard W. Selby, Microsoft secrets : how the world's most powerful software company creates technology, shapes markets, and manages people, Free Press, New York, 1995. 
Czarniawska, B. and C. Mazza, "Consulting as a liminal space," Human Relations, 56, 3, (2003), 267-290.

Davidson, Elizabeth J, "Technology frames and framing: A socio-cognitive investigation of requirements determination," MIS Quarterly, 26, 4, (2002), 329.

Dougherty, Deborah, "Interpretive Barriers to Successful Product Innovation in Large Firms," Organization Science, 3, 2, (1992), 179-202.

Elkjaer, B., P. Flensburg, J. Mouritsenand H. Willmott, "The Commodification of Expertise: The Case of Systems Development Consulting," Accounting, Management and Information Technologies, 1, 2, (1991), 139-156.

Epstein, Jason, Book business: publishing past, present, and future, W.W. Norton, New York, 2001.

Faraj, Samar and Lee Sproull, "Coordinating Expertise in Software Development Teams," Management Science, 46, 12, (2000), 1554-1568.

Gable, Guy G. and Wynne W. Chin, "Client Versus Consultant Influence on Client Involvement in Computer System Selection Projects: A Two-Actor Model of The Theory of Planned Behavior," Proceedings of the TwentySecond International Conference on Information Systems, New Orleans, LA, 2001, 249-260.

Giddens, Anthony, The constitution of society: outline of the theory of structuration, University of California Press, Berkeley, 1984.

Glaser, Barney G. and Anselm L. Strauss, The discovery of grounded theory; strategies for qualitative research, Aldine Pub. Co., Chicago, IL, 1967.

Guinan, Patricia, S. Coopriderand Samar Faraj, "Enabling software development team performance during requirement definition: A behavioral versusu technical approach," Information Systems Research, 9, (1998), 101-125.

Hart, Oliver D., Firms, contracts, and financial structure, Oxford University Press, Oxford, 1995.

Henderson, Katherine, "Flexible Sketches and Inflexible Data Bases: Visual Communication Conscription Devices, and Boundary Objects in Design Engineering," Science, Technology, \& Human Value, 16, 4, (1991), 448473.

livari, Juhani, R. A. Hirschheimand Heinz Klein, "A Paradigmatic Analysis of Contrasting Information Systems Development Approaches and Methodologies," Information Systems Research, 9, 2, (1998), 164-193.

Jacobson, Ivar, Object-oriented software engineering: a use case driven approach, ACM Press, New York, NY, 1993.

Kemerer, Chris L., Software Project Management, McGrawHill, Boston, 1997.

Killman, R. and K. Thomas, "Interpersonal conflict-handling behavior as reflections of Jungian personality dimensions," Psychological Reports, 37, (1975), 971- 980.

Kim, Jeffrey Y. and John L. King, "Boundary Instances in Heterogeneous Engineering Teams: Trouble Management in the Dram Manufacturing Process," Research on Managing Groups and Teams, 3, (2000), 79-98.

Kirsch, Laurie J., "The management of complex tasks in organizations: Controlling the systems development process," Organization Science, 7, 1, (1996), 1-21.

Kirsch, Laurie, V. Sambamurthy, Dong-Gil Koand Russel Purvis, "Controlling Information Systems Development Projects: The View from the Client," Management Science, 48, 4, (2002), 484-498.

Kraut, Robert E. and Lynn A. Streeter, "Coordination in Software Development," Communications of the ACM, 38, 3 , (1995), 69-81.

Kyng, Morten, "Representations of work: Making representations work," Association for Computing Machinery. Communications of the ACM, 38, 9, (1995), 46-56.

Lee, A. S. and R. L. Baskerville, "Generalizing generalizability in information systems research," Information Systems Research, 14, 3, (2003), 221-243.

Leonard, Dorothy and Walter C. Swap, When sparks fly: igniting creativity in groups, Harvard Business School Press, Boston, Mass., 1999.

Levina, Natalia, "Multi-party Information Systems Development: The Challenge of Cross-Boundary Collaboration," unpublished Doctoral Dissertation, Massachusetts Institute of Technology, 2001.

Levina, Natalia and Jeanne W. Ross, "From the Vendor's Perspective: Exploring the Value Proposition in IT Outsourcing," MIS Quarterly, 27, 3, (2003), 331-364.

March, James G., "Exploration and exploitation in organizational learning," Organization Science, 2, (1991), 71-87.

Markus, M.L., "Power, Politics, and MIS Implementation," Communications of the ACM, 26, 6, (1983), 430-444.

Miles, Matthew B. and A. M. Huberman, Qualitative Data Analysis: A Sourcebook of New Methods, Sage Publications, Beverly Hills, 1984. 
Newman, M. and F. Noble, "User Involvement as an Interaction Process: A Case Study," Information Systems Research, 1, 1, (1990), 89-113.

Newman, M. and D. Robey, "A Social-Process Model of User-Analyst Relationships," Mis Quarterly, 16, 2, (1992), 249-266.

Orlikowski, W. J., "Using technology and constituting structures: A practice lens for studying technology in organizations," Organization Science, 11, 4, (2000), 404-428.

Orlikowski, Wanda J, "The Duality of Technology: Rethinking the Concept of Technology in Organizations," Organization Science, 3, 3, (1992), 398-427.

Orlikowski, Wanda J, "Knowing in practice: Enacting a collective capability in distributed organizing," Organization Science, 13, 3, (2002), 249.

Orlikowski, Wanda J and Debra C. Gash, "Technological Frames: Making Sense of Information Technology in Organizations," ACM Transactions on Information Systems, 12, 2, (1994), 174-207.

Pawlowski, Suzanne D., Dan Robeyand Arjan Raven, "Supporting Shared Information Systems: Boundary Objects, Communities, and Brokering," Proceedings of the Twenty-First International Conference on Information Systems, Brisbane, Australia, 2000, 329-338.

Polzer, J. T., L. P. Miltonand W. B. Swann, "Capitalizing on diversity: Interpersonal congruence in small work groups," Administrative Science Quarterly, 47, 2, (2002), 296-324.

Reagans, R. and E. W. Zuckerman, "Networks, diversity, and productivity: The social capital of corporate R\&D teams," Organization Science, 12, 4, (2001), 502-517.

Robey, D., "Modeling Interpersonal Processes During System-Development - Further Thoughts and Suggestions," Information Systems Research, 5, 4, (1994), 439-445.

Robey, D. and M. L. Markus, "Rituals in Information System Design," MIS Quarterly, March, (1984), 5-15.

Robey, D., L. Smithand L. Vijaysarathy, "Perceptions of Conflict and Success in Information Systems Development Projects," Journal of Management Information Systems, 10, 1, (1993), 123-139.

Sabherwal, R. and D. Robey, "An Empirical Taxonomy of Implementation Processes Based on Sequences of Events in Information System Development," Organization Science, 4, 4, (1993), 548-576.

Sabherwal, Rajiv, "The Role of Trust in Outsourced IS Development Projects," Communications of the ACM, 42, 2, (1999), 80-86.

Sambamurthy, V. and L. J. Kirsch, "An integrative framework of the information systems development process," Decision Sciences, 31, 2, (2000), 391-411.

Schmidt, Kjeld, "Of maps and scripts-the status of formal constructs in cooperative work," Proceedings of the Proceedings of the international ACM SIGGROUP conference on Supporting group work : the integration challenge, Phoenix, Arizona, United States, 1997, 138--147.

Schmidt, Kjeld and L Bannon, "Taking CSCW seriously - supporting articulation work," Computer Supported Cooperative Work, 1, 1\&2, (1992), 7-40.

Schön, Donald A., The reflective practitioner: how professionals think in action, Basic Books, New York, 1983.

Schrage, Michael, Serious play : how the world's best companies simulate to innovate, Harvard Business School Press, Boston, 2000.

Schwartzman, Helen B., Ethnography in organizations, Sage Publications, Newbury Park, Calif., 1993.

Star, S. L. and J. R. Griesemer, "Institutional Ecology, 'Translations' and Boundary Objects: Amateurs and Professionals in Berkeley's Museum of Vertebrate Zoology 1907-39," Social Studies of Science, 19, (1989), 387-420.

Star, Susan Leigh, "The Structure of III-Structured Solutions: Boundary Objects and Heterogeneous Distributed Problem Solving," In Readings in Distributed Artificial Intelligence, M. Huhn and L. Gasser (Ed.), Morgan Kaufman, Menlo Park, CA, 1989, 37-54.

Terwiesch, Christian and Christoph H Loch, "Collaborative Prototyping and the Pricing of Custom-Designed Products," Management Science, 50, 2, (2004), 145.

Van Maanen, J., "The Fact of Fiction in Organizational Ethnography," Administrative Science Quarterly, 24, (1979), 539-550.

Van Maanen, John and Stephen Barley, "Occupational Communities: Culture and Control in Organizations," In Research in Organizational Behavior, L. L. Cummings and B. M. Straw (Ed.), 6, JAI Press, Greenwich, CT, 1984, 287-365. 
von Hippel, Eric, The sources of innovation, Oxford University Press, New York, 1988.

Wastell, David G, "Learning dysfunctions in information systems development: Overcoming the social defenses with transitional objects," MIS Quarterly, 23, 4, (1999), 581.

Yakura, Elaine, "Practices of Power: Meaning and Legitimation in Information Technology Consulting," unpublished

Ph.D. Dissertation, Massachusetts Institute of Technology, 1993.

Zuboff, Shoshana, In the age of the smart machine: the future of work and power, Basic Books, New York, 1988.

\section{Figures}
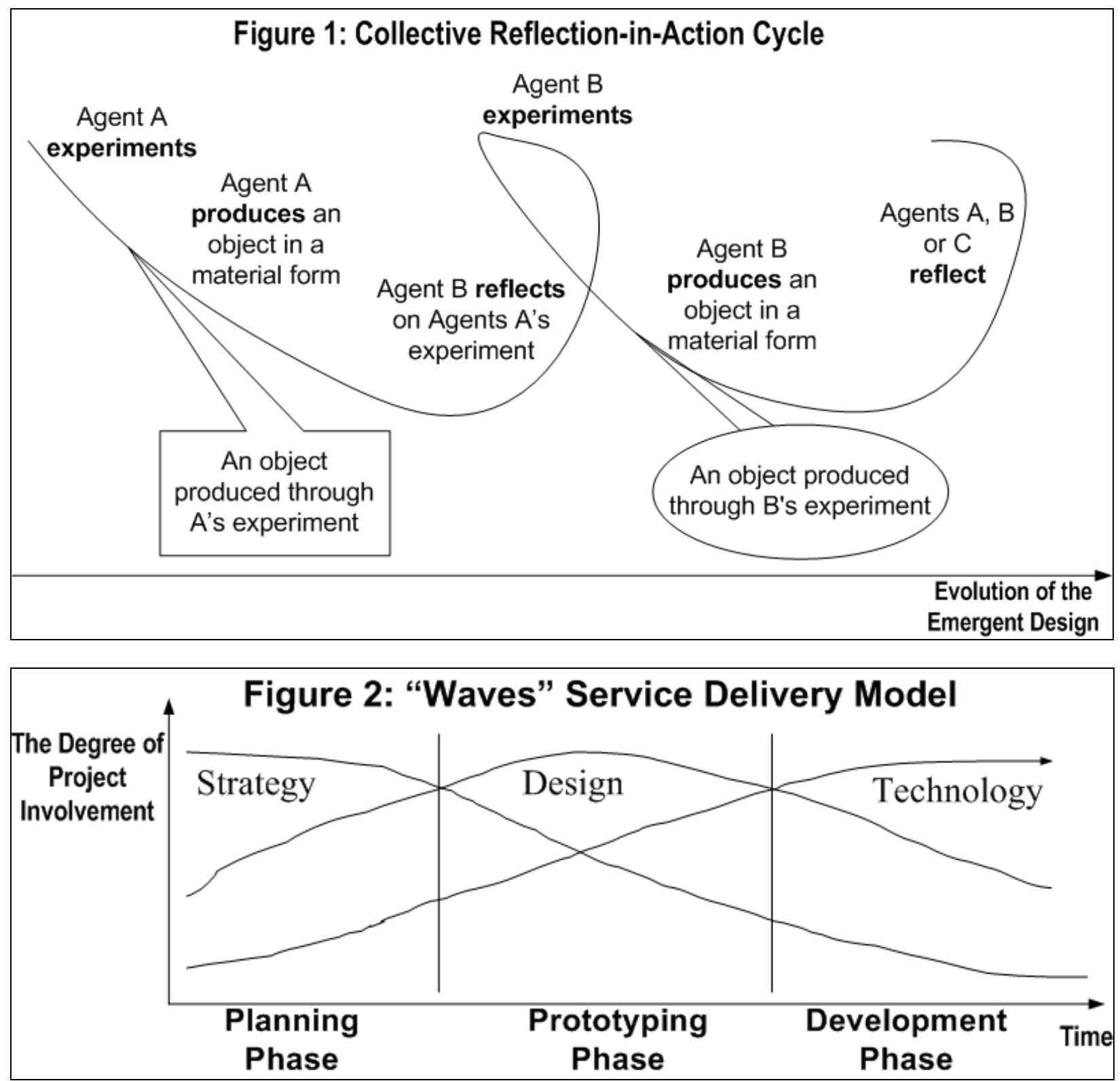
Figure 4: Team's Composition and Deliverables

\begin{tabular}{|c|c|c|c|}
\hline Phases & $\begin{array}{c}\text { Business } \\
\text { Development }\end{array}$ & Planning & Prototyping \\
\hline Duration & $\begin{array}{c}\text { October 1999- January } 2000 \\
3.5 \text { months }\end{array}$ & $\begin{array}{c}\text { January } 2000 \text { - March } \\
2000 \\
7 \text { weeks } \\
\end{array}$ & $\begin{array}{c}\text { March } 2000 \text { - June } 2000 \\
13 \text { weeks }\end{array}$ \\
\hline $\begin{array}{l}\text { Eserve Team } \\
\text { Composition }\end{array}$ & $\begin{array}{ll}- & \text { Account Manager } \\
- & 1 \text { Sr. Strategist } \\
- & 1 \text { Jr. Strategists } \\
- & 1 \text { Jr. Technologist }\end{array}$ & $\begin{array}{ll}\text { - } & \text { Account Manager } \\
\text { - } & \text { Planning Project } \\
& \text { Manager } \\
\text { - } & \text { 3 Jr. Strategists } \\
\text { - } & \text { 1 Jr. Technologist } \\
\text { - } & \text { 1/2 Sr. Technologist } \\
\text { - } & \text { 1/2 Brand Specialist }\end{array}$ & $\begin{array}{ll}\text { - } & \text { Account Manager } \\
\text { - } & \text { Prototyping Project } \\
\text { - } & \text { Manager } \\
\text { - } & \text { 2 1/2 Jr. Strategists } \\
\text { - } & 1 \text { Jr. Technologist } \\
- & 2 \text { Jr. Dechnologist } \\
- & 1 \text { Jr. Information } \\
& \text { Architect } \\
\text { - } & \text { 1/2 Brand Specialist }\end{array}$ \\
\hline $\begin{array}{l}\text { Pubco Core } \\
\text { Team } \\
\text { Composition }\end{array}$ & $\begin{array}{ll}\text { - } & \text { Top Executive } \\
\text { - } & \text { Finance VP } \\
\text { - } & \text { 4 Sales and Marketing } \\
& \text { Mgrs } \\
\text { - } & 1 \text { Editorial Mgr }\end{array}$ & $\begin{array}{ll}\text { - } & \text { Finance VP } \\
\text { - } & \text { Pubco Project Manager } \\
\text { - } & \text { 2 Sales and Marketing } \\
& \text { Mgrs } \\
\text { - } & \text { 1 Editorial Mgr } \\
\text { - } & \text { 1 Print Production Mgr } \\
\text { - } & \text { 1 IT Mgr } \\
\text { - } & \text { 2 Web Group Mgrs }\end{array}$ & $\begin{array}{ll}\text { - } & \text { Finance VP } \\
\text { - } & \text { Pubco Project Manager } \\
\text { - } & \text { 2 Sales and Marketing } \\
& \text { Mgrs } \\
\text { - } & \text { 1 Editorial Mgr } \\
\text { - } & \text { 1 Print Production Mgr } \\
\text { - } & \text { 2 IT Mgr } \\
\text { - } & \text { 2 Web Group Mgrs }\end{array}$ \\
\hline Deliverables & $\begin{array}{ll}\text { - } & \text { Sales Presentation } \\
\text { - } & \text { Agreement on Scope and } \\
\text { - } & \text { Price (Statement of Work) } \\
\text { Contract }\end{array}$ & $\begin{array}{ll}\text { - } & \text { Customer Segmentation } \\
\text { - } & \text { Cunalysis } \\
& \text { Report } \\
\text { - } & \text { Market Trend Analysis } \\
\text { - } & \text { Initiative Selection } \\
- & \text { Functionality } \\
\text { - } & \text { Prioritization } \\
\text { Assessment of existing } \\
\text { - } & \text { technological initiatives } \\
& \text { Technology Platform } \\
& \text { Selection }\end{array}$ & $\begin{array}{ll}\text { - } & \text { Use Cases } \\
\text { - } & \text { New Site Map } \\
\text { - } & \text { Style Guide } \\
\text { - } & \text { Click-through Mockup } \\
\text { - } & \text { Prototype of One } \\
& \text { Functionality } \\
\text { - } & \text { Technical Architecture } \\
\text { - } & \text { Usability Test Report }\end{array}$ \\
\hline
\end{tabular}




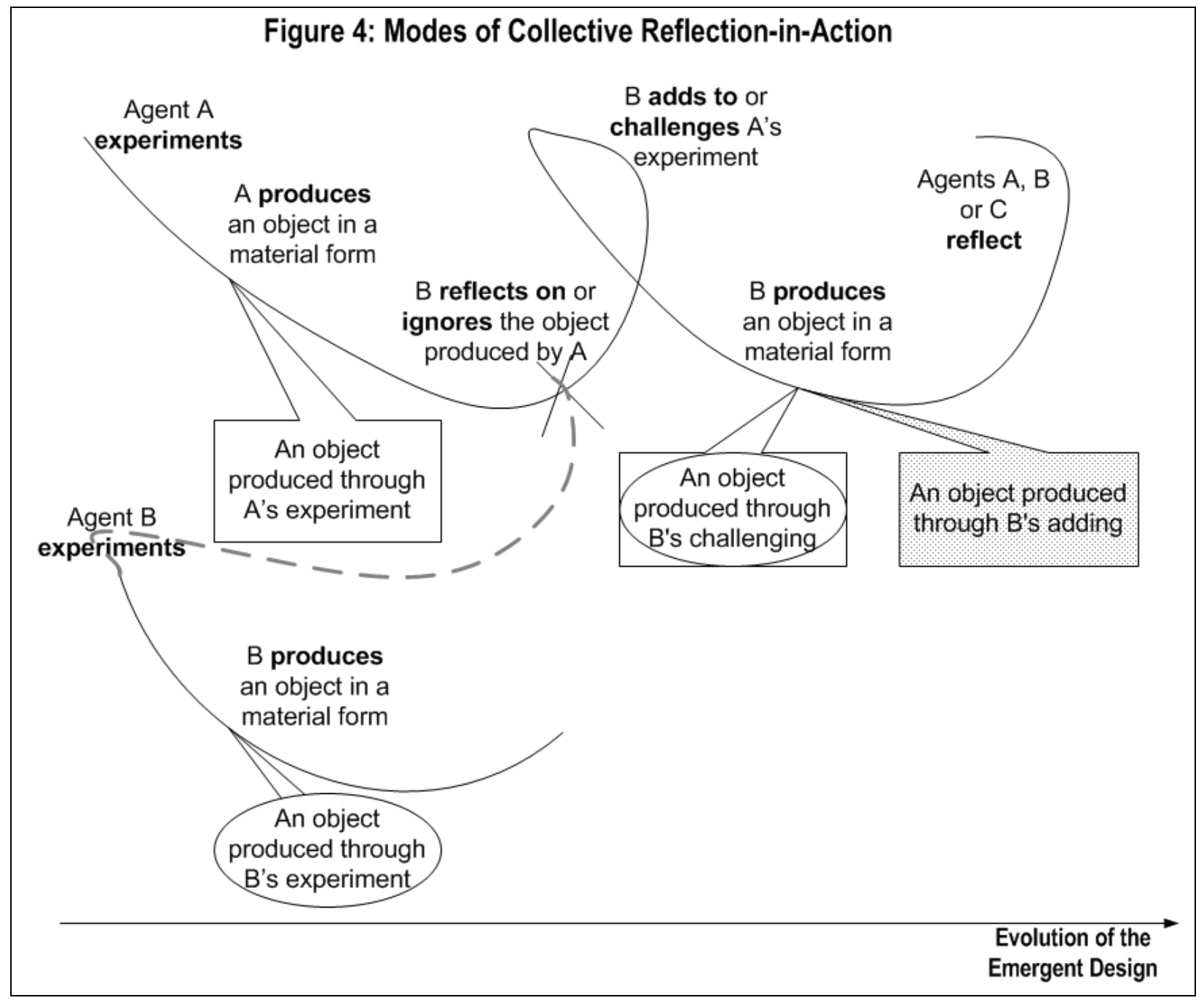

\section{Figure 5: Collaborative Practice in Multi-party ISD}

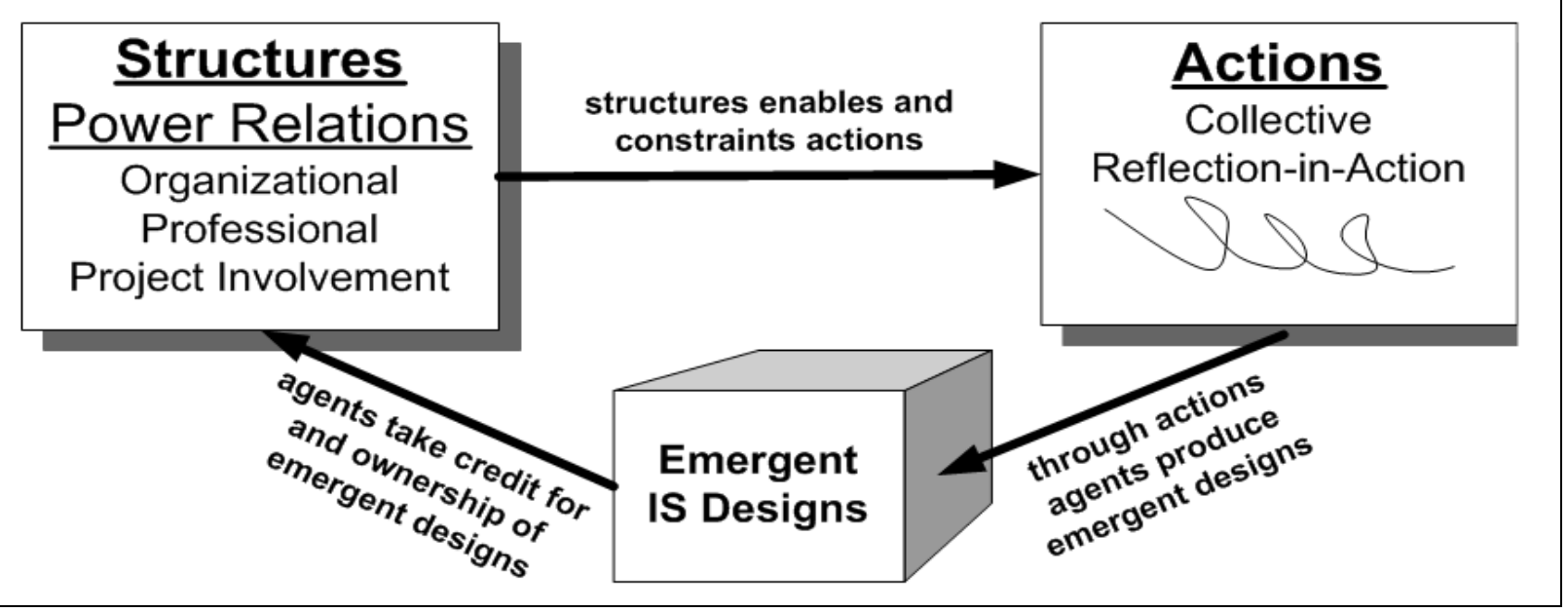

